\title{
MELHORIAS OPERACIONAIS EM UM RESTAURANTE UNIVERSITÁRIO: UM ENFOQUE DE MÚLTIPLAS ABORDAGENS
}

\author{
Clara Cruz Neves (UFS) \\ ccrune97@gmail.com \\ Celso Satoshi Sakuraba (UFS) \\ sakuraba@ufs.br \\ Pablo Victor de Oliveira Souza (UFS) \\ victo_pablo@hotmail.com \\ Alan Barreto Santos (UFS) \\ allanbt15@gmail.com \\ Victor Hugo Pianco de Oliveira (UFS) \\ vhpdo1@gmail.com
}

\begin{abstract}
Muitas universidades públicas brasileiras oferecem alimentação para seus estudantes e funcionários. O serviço pode ser prestado em diferentes modelos, havendo um enfoque no qual há um self-service parcial, que é o modelo adotado pelo restaurante universitário da Universidade Federal de Sergipe, o objeto de estudo utilizado. O objetivo da presente pesquisa foi desenvolver propostas de melhorias no âmbito operacional que possam ser implementadas no local estudado. Através da utilização de algumas ferramentas da qualidade, como Diagrama de Ishikawa, Brainstorming e Fluxogramas, foi possivel sugerir propostas que sanasse os problemas identificados. Dessa forma, cabe à administração do restaurante, junto à universidade, avaliar a disponibilidade de recursos para que as sugestões sejam implementadas.
\end{abstract}

Palavras-chave: Fluxograma, Diagrama de Ishikawa, Layout, campanha de conscientização. 


\section{Introdução}

Em muitos estados do Brasil, podem-se encontrar universidades públicas que oferecem refeições aos seus estudantes e funcionários. Este serviço é comumente oferecido na forma self-service, em que o próprio cliente, também denominado comensal, se serve de alguns ou todos os seus alimentos. Em algumas universidades públicas no Brasil, o serviço de restaurante universitário é prestado tanto nos modelos tradicionais, onde há um funcionário do restaurante servindo as porções, até os modelos de self-service parcial, onde o comensal se serve de alguns dos alimentos.

O presente trabalho tem por objetivo desenvolver propostas de melhorias no restaurante universitário da Universidade Federal de Sergipe (UFS), também conhecido como RESUN. Além de lidar com o problema maior, que era o tempo gasto para que os comensais realizassem suas refeições, buscou-se também a conscientização sobre a importância das boas práticas para um melhor desempenho e qualidade deste serviço.

A motivação para elaboração deste estudo surgiu a partir de uma demanda do Diretório Central dos Estudantes da UFS (DCE) à reitoria por um serviço de restauração que não prejudicasse os horários de aulas dos alunos. A reitoria requisitou ao Departamento de Engenharia de Produção a formação de uma força-tarefa primeiramente para o levantamento das causas de problemas identificados pela gestão do RESUN. Algumas ferramentas da qualidade são utilizadas para auxiliar na identificação de tais problemas, bem como apontar possíveis falhas práticas acometidas durante o processo de fornecimento do serviço. Após levantadas essas causas, foram buscadas alternativas de melhorias de baixo custo que pudessem ser implementadas no restaurante.

\section{Referencial teórico}

Nesta seção serão evidenciados e explicitados termos e ferramentas utilizados como base para a análise da conjuntura operacional do RESUN.

\subsection{Ferramentas da qualidade aplicadas a serviço}


A qualidade de produtos e serviços pode ser mensurada através de métodos e ferramentas específicas a fim de, por exemplo, ocasionar o aumento de sua produção. Duas dessas ferramentas mais tradicionais são o Diagrama de Ishikawa e o fluxograma de processo (JOZSEF e BLAGA, 2012).

O Diagrama de Ishikawa, também conhecido como espinha de peixe, consiste de uma forma de delinear os principais fatos de uma determinada situação (DOBRUSSKIN, 2016; DIGILIO et al., 2016). Além disso, ele pode ser caracterizado como sendo uma ferramenta da qualidade que organiza os possíveis causadores de um problema e seus efeitos de forma gráfica e sistemática (DHAT et al., 2017).

Ao serem identificados, os problemas devem ser categorizados nos parâmetros do Diagrama de Ishikawa, que em geral são: matéria prima, condições de trabalho, gestão material e trabalhadores (EELEUCH et al., 2016). Segundo Mukharya et al. (2013), após uma avaliação do diagrama é possível adquirir uma maior ciência do processo, o que permite o desenvolvimento apropriado de uma estratégia de controle.

Como exemplo prático, a aplicação do Diagrama de Ishikawa em uma empresa alimentícia da Macedônia possibilitou uma melhoria na qualidade do produto e um aumento na produtividade, assim como um aprimoramento no quesito custos de qualidade (MITREVA et al., 2016). Dessa forma, a presente pesquisa buscou utilizar a mesma ferramenta para analisar o serviço prestado pelo RESUN-UFS.

Além do Diagrama de Ishikawa, outro método utilizado é o fluxograma. Esta ferramenta é utilizada como representação gráfica de todo o processo que se está analisando, utilizando símbolos gráficos que descrevem os diversos fluxos sequenciais existentes (CITISYSTEMS, 2017; JORGE e MIYAKE, 2016). Dentre os diferentes tipos de fluxogramas, o modelo mais utilizado é o que adota "raias" para indicar qual órgão ou entidade é responsável pelo desenvolvimento de cada atividade (JORGE E MIYAKE, 2016).

Existem diferentes linguagens que podem ser utilizadas na elaboração de um fluxograma, sendo uma das mais conhecidas a BPM (Business Process Model). Neste tipo de prática, tem-se por finalidade descrever, analisar e melhorar determinadas operações 
comerciais, de forma a ser possível identificar erros e gargalos no processo (KEMSLEY, 2015).

\subsection{Rearranjo do layout}

Além das ferramentas da qualidade utilizadas, outra questão abordada durante o desenvolvimento do projeto foi a análise e rearranjo do layout. O layout, palavra em inglês para arranjo físico, é toda a distribuição física dos recursos da organização, como equipamentos, estoques, mesas de trabalho, entre outros (MARTINS e LAUGENI, 2005). Os problemas de layout são uma classe de problemas na qual se busca o arranjo ideal de departamentos e recursos de uma forma geral para a diminuição de custos. Por terem um impacto significativo na eficiência de diversos processos produtivos, os layouts vêm sendo estudado durante várias décadas, principalmente depois dos anos 1960 (ANJOS e VIEIRA, 2017).

De acordo com Cury (2000), o estudo de layout tem como objetivos principais a otimização das condições de trabalho, a racionalização dos fluxos de fabricação e da tramitação de processos e a melhor disposição física de postos de trabalho, com aproveitamento de todo o espaço e minimização da movimentação de pessoas, produtos e materiais de uma forma geral. Para se atingir os objetivos supracitados, é preciso que o projeto de layout siga alguns estágios:

- Levantamento: a equipe responsável analisará as plantas da área, os recursos envolvidos no processo, os fluxos de pessoas e coletará dados, realizando questionários e entrevistas quando necessário;

- Crítica do levantamento: neste estágio, a equipe analisará os principais problemas para se atingir os objetivos, dando ênfase às discrepâncias encontradas entre as documentações da empresa e o que é realizado na prática, além de elaborar os fluxos da situação e confrontá-los com regulamentos e normas;

- Planejamento da solução: nesta fase, todos os dados coletados e fluxos determinados serão analisados para se realizar a intervenção de forma mais eficaz e otimizada possível, além de determinar custos de mudanças e realizar desenhos em escala do espaço considerado com as respectivas modificações expostas; 
- Crítica do planejamento: neste momento, o projeto desenvolvido será apresentado aos colaboradores que utilizarão o novo espaço, a fim de obter opiniões e críticas de quem está envolvido diretamente na atividade;

- Implantação: com a aprovação do novo layout, esta fase pode ser considerada uma das mais importantes, pois nela o projeto será implantado e os colaboradores treinados (se necessário) a fim de adaptá-los ao novo ambiente;

- Controle de resultados: este estágio nada mais é que o acompanhamento dos resultados obtidos com a implantação do novo arranjo físico, verificando se há necessidade de alguma mudança.

Segundo Zhang et al. (2017), a expansão física e a modificação do ambiente são algumas das estratégias que podem ser usadas para resolver problemas de gestão de capacidade. Em um estudo realizado em um parque temático na China, foi percebido que um espaço bem projetado poderia otimizar a capacidade de transporte do parque e diminuir o tempo de espera, reduzindo o congestionamento de pessoas. Esta abordagem pode ser trazida ao ambiente de um restaurante universitário, fazendo com que um novo rearranjo físico apresente melhorias de desempenho e qualidade do serviço.

Com um projeto de layout, é possível definir a melhor forma de se arranjar mesas e cadeiras de modo a otimizar o espaço, permitindo um melhor tráfego de comensais de acordo com normas preestabelecidas. A curto prazo, pode haver uma dificuldade de adaptação dos comensais ao novo arranjo; contudo, este tipo de problema é verificado com a etapa de controle de resultados e pode ser extinto com ajuda de sinalização e comunicação/treinamento.

\subsection{Importância da conscientização no ambiente organizacional}

Outra questão de suma importância para o êxito de um projeto é a conscientização dos usuários da organização, a fim de evitar práticas indesejadas que prejudiquem o bom funcionamento de seu setor produtivo e/ou de serviços. $\mathrm{O}$ ambiente atual em que as empresas operam tem presenciado o surgimento de novos papéis que devem ser desempenhados como 
resultado de alterações nos valores e ideologias de nossa sociedade. Como consequências das inovações ocorridas no setor produtivo, surgiram nas últimas décadas novas exigências para a educação, levando a uma nova relação entre educação e trabalho (FILHO, 1994; LEITE, 1995; MACHADO, 1994).

Segundo Dupuis (1996), assistimos hoje a transformações importantes no ambiente de trabalho. Cada vez mais os funcionários são convidados a vestir a camisa da empresa. Para isso, devem estar conscientes e engajados com os valores organizacionais e principalmente com um trabalho de conscientização, que se inicia no momento de inserção do empregado no ambiente organizacional.

Do ponto de vista social, o estabelecimento ou não da ordem resulta do compartilhamento que ocorre na interação humana. Do ponto de vista individual, a identidade é elemento chave da realidade subjetiva e se encontra em relação com a sociedade. Nesta acepção, o indivíduo é produto e produtor do sistema social (ZANELLI, 2003).

Um excelente ambiente de trabalho não é benefício apenas para os funcionários; profissionais bem conscientizados no ambiente organizacional possuem melhores condições de levar a companhia a uma maior produtividade, inovação, competitividade e rentabilidade.

Trabalhar com o público interno tornou-se imprescindível para as empresas, e a conscientização, seja dos funcionários ou dos clientes, é vital para a organização. Mais do que defender a organização, funcionários e colaboradores devem ser estimulados a adotar os valores e comportamentos éticos através de ações estratégicas fundamentadas pela empresa, para que esta obtenha um maior sucesso (SCHERMERHORN, 1999).

\section{Procedimentos metodológicos}

O método de pesquisa utilizado foi o qualitativo, tendo como foco uma compreensão detalhada sem levar em consideração a representatividade numérica de uma determinada amostra, organização, etc. (GERHARDT e SILVEIRA, 2009). Para a coleta de dados foram utilizadas observações diretas, entrevistas não-formais (não-estruturadas) e aplicação de 
questionários. Para o levantamento das causas aplicou-se a técnica brainstorming e o Diagrama de Ishikawa. A Figura 1 mostra a sequência de etapas realizadas neste trabalho.

Figura 1 - Etapas da metodologia adotada

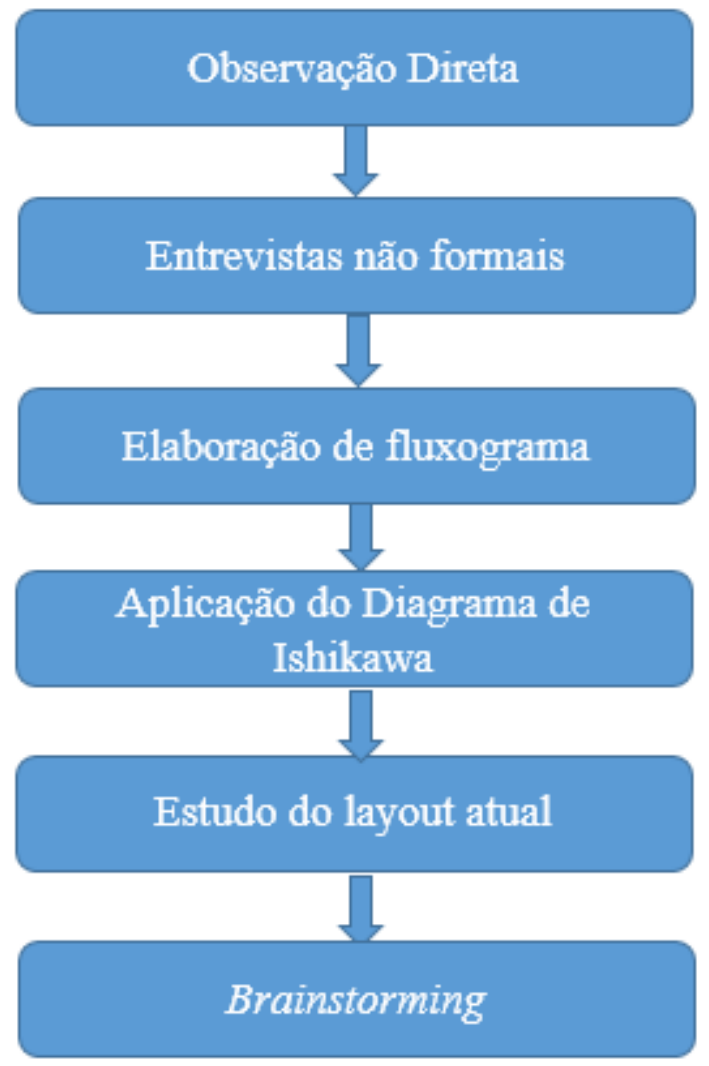

Fonte: autoria própria

O método observacional é um dos métodos mais utilizados no meio científico, representando em geral a primeira etapa do levantamento de informações. Ele consiste em observar algo que acontece ou já aconteceu para o levantamento inicial das hipóteses (GIL, 2008). Após as observações, foram realizadas entrevistas com os principais gestores do RESUN: seu diretor e uma das nutricionistas responsáveis. Estas etapas serviram para a análise da planta atual do refeitório do restaurante e para a identificação de possíveis pontos críticos e problemas a serem abordados. 
Foi elaborado um fluxograma de todo o processo para uma melhor compreensão e visualização do mesmo, seguido de um Diagrama de Ishikawa para determinação das principais causas dos problemas encontrados. Um estudo das plantas e disposição do layout atual também foi conduzido.

Por fim, foi realizado um brainstorming para a elaboração de soluções para os problemas encontrados. Segundo Rotondaro, Cauchick e Gomes (2010), brainstorming é uma técnica muito utilizada em desenvolvimento de produtos, serviços ou processos. Ela consiste em extrair dados e informações a partir de um conjunto de ideias elaboradas por um grupo de pessoas. Esta técnica foi utilizada principalmente para a identificação dos pontos críticos e posteriormente para o desenvolvimento de soluções e construção do novo layout.

\section{Análise e discussão dos resultados}

O RESUN está localizado no campus de São Cristóvão da UFS, próximo à capital do estado de Sergipe. Atualmente, atende uma média de 2.800 comensais entre 11:00 e 14:00 horas no almoço e 1.800 entre 17:00 e 19:00 no jantar. O modelo de serviço adotado pelo RESUN é o self-service parcial, fornecido por uma empresa terceirizada. As proteínas, bebidas e sobremesas são servidas por copeiras enquanto os próprios comensais se servem do restante dos alimentos. Apesar de utilizado por muitas universidades, este modelo favorece a formação de filas, pois a chegada de comensais ocorre de forma repentina em horários de picos de acordo com os horários das aulas.

O RESUN possui dois refeitórios onde os comensais se sentam para comer, um no térreo e outro no primeiro andar. O foco deste trabalho está no andar térreo, onde ocorre todo o processo de serviço e também onde se encontram e a maior parte dos assentos. Os comensais entram no sistema através de uma fila única, que se divide posteriormente em quatro filas paralelas onde eles se servem de salada, arroz, feijão e guarnição. Em seguida, as filas são agrupadas duas a duas para que as copeiras sirvam a proteína, e por fim os comensais passam por uma mesa onde recebem o suco e a sobremesa.

\subsection{Aplicação das ferramentas da qualidade e análise do layout}


Durante as entrevistas com os gestores do RESUN, foram verificados outros problemas além do demasiado tempo de fila, tais como: falta de higienização dos comensais (que por muitas vezes não lavavam as mãos antes das refeições), desperdício de alimentos e falta de separação do lixo em reciclável e não reciclável. Percebeu-se que mesmo os próprios funcionários do RESUN não sabiam direito os critérios de separação do lixo, orientando os comensais a jogarem o guardanapo orgânico juntamente com o copo plástico reciclável.

Para melhor entendimento do processo de autosserviço do RESUN, foi elaborado um mapeamento do processo por meio de um fluxograma, utilizando a notação BPMN. Este fluxograma pode ser visualizado na Figura 2. 
Figura 2 - Fluxograma do processo de autosserviço do RESUN.

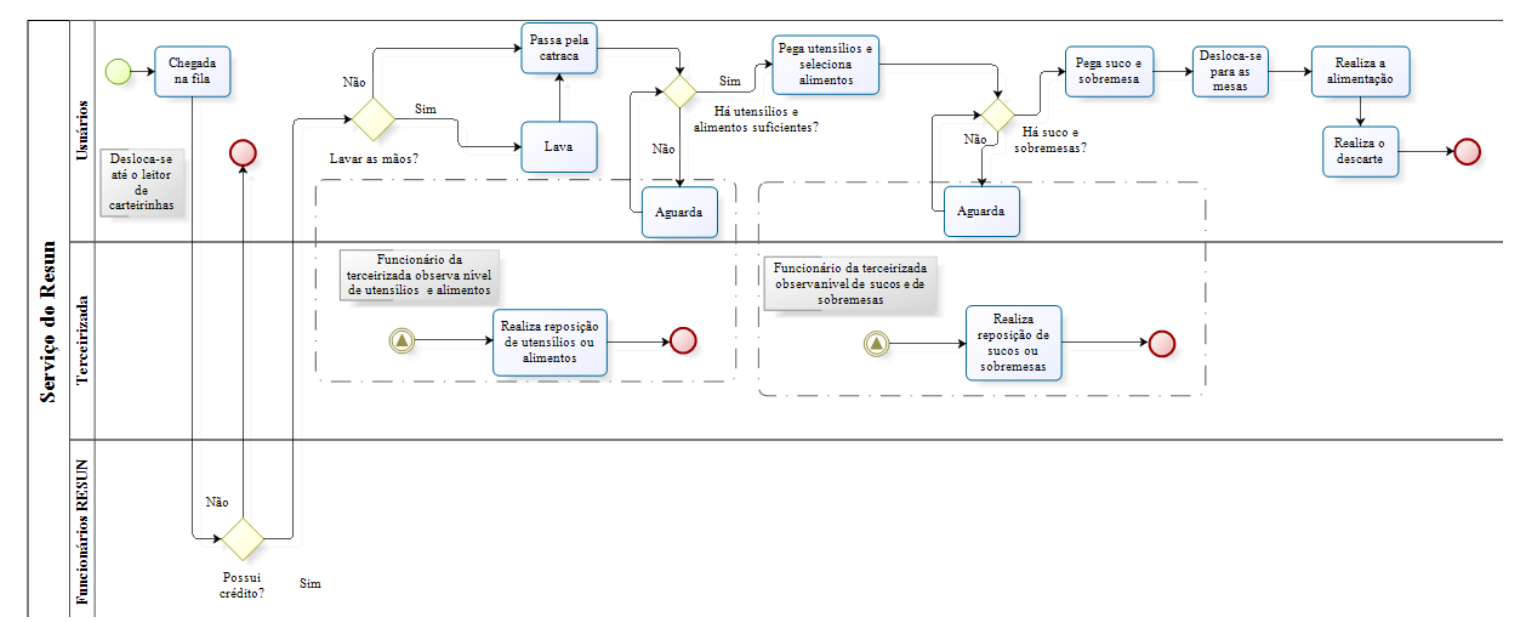

Fonte: autoria própria

Ao observar o fluxograma, percebe-se que há alguns pontos de decisão sobre os quais os comensais não possuem controle. Muitos deles dependem diretamente dos funcionários da empresa terceirizada, pois são estes que realizam o setup do processo, ou seja, a troca de cubas de alimentos quando estes se acabam ou estão prestes a acabar. Essas decisões podem vir acompanhadas de pequenas paradas, o que pode contribuir para um maior tempo de permanência do comensal no processo e consequentemente do tempo médio de espera na fila. Para determinar outras causas do tempo excessivo de filas, considerado o problema principal, foi gerado o Diagrama de Ishikawa apresentado na Figura 3.

Figura 3 - Diagrama de Ishikawa para o longo tempo de espera na fila 


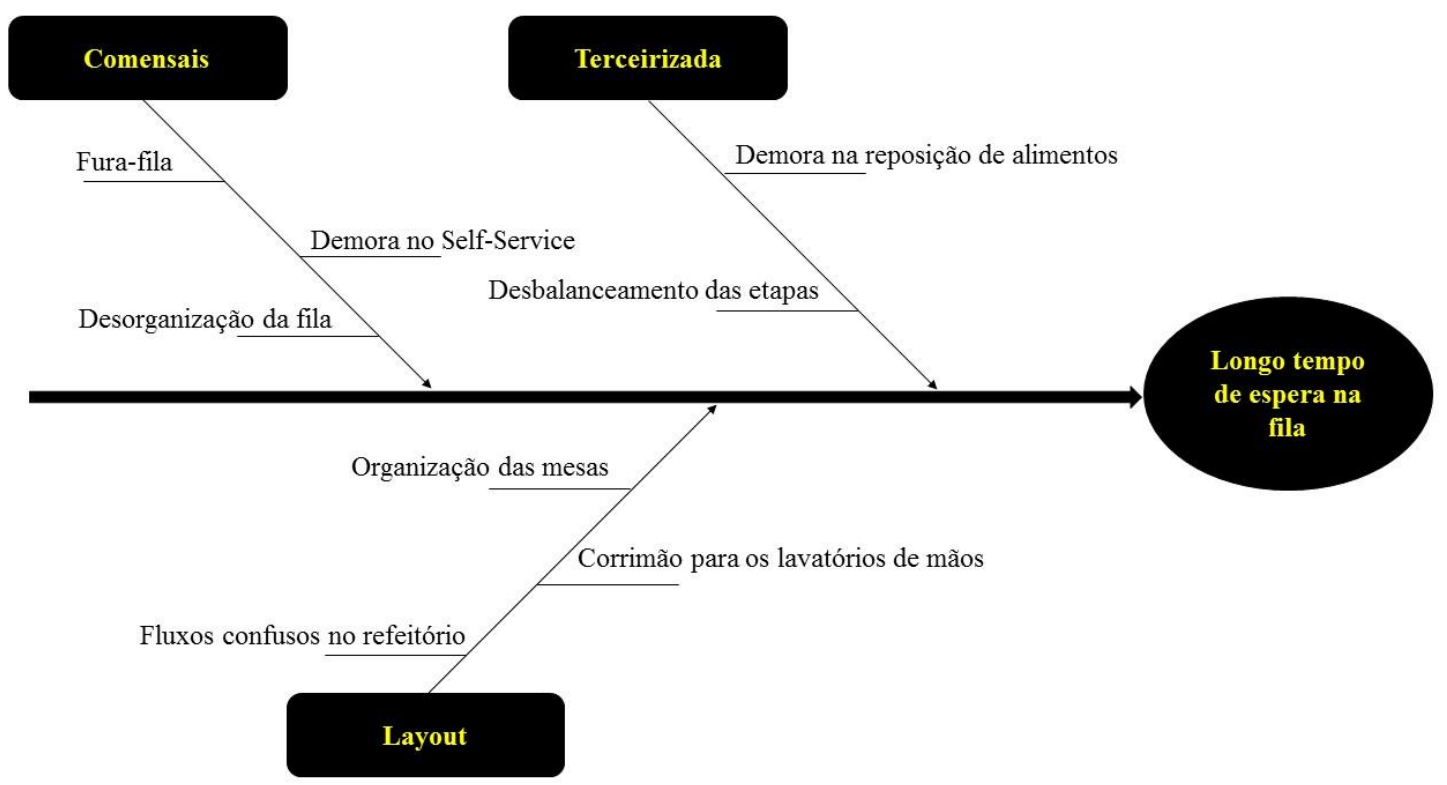

Fonte: autoria própria

As causas foram classificadas no diagrama conforme os elementos responsáveis pelas mesmas para facilitar o trabalho posterior de elaboração de soluções. Dentre as causas relacionadas ao próprio comportamento dos comensais estão: os "fura-filas", comensais que não respeitam a sequência da fila aumentando o tempo médio de espera de todos aqueles em posições posteriores; a demora no self-service, ocasionada por comensais que gastam um tempo maior do que a média se servido para escolherem porções específicas do alimento; e a desorganização da fila, principalmente na entrada do restaurante, onde os comensais costumam se aglomerar no início do funcionamento.

Dentre as causas relacionadas à empresa terceirizada estão a demora na reposição dos alimentos e o desbalanceamento das etapas do processo, causada pela formação de uma quantidade diferente de filas em cada etapa. A primeira causa relacionada ao layout é o corrimão metálico paralelo às pias na entrada do restaurante onde se lavam as mãos, instalado ainda quando o restaurante tinha um fluxo diferente. Esse corrimão obriga os comensais a saírem da fila uma vez para lavarem as mãos e retornarem a ela em seguida como mostra a Figura 4, gerando confusão e fazendo com que muitos deixem de lavar as mãos. As outras duas causas são os corredores estreitos e a disposição das mesas sem muito espaço para os 
comensais, que acabam gerando fluxos confusos dentro dos refeitórios fazendo com que os usuários percam mais tempo com o deslocamento e causando acidentes.

Figura 4 - Corrimão metálico que obriga os comensais que entram pelo corredor à esquerda da foto a se deslocarem para a direita para lavarem as mãos e depois para a esquerda de novo para entrarem

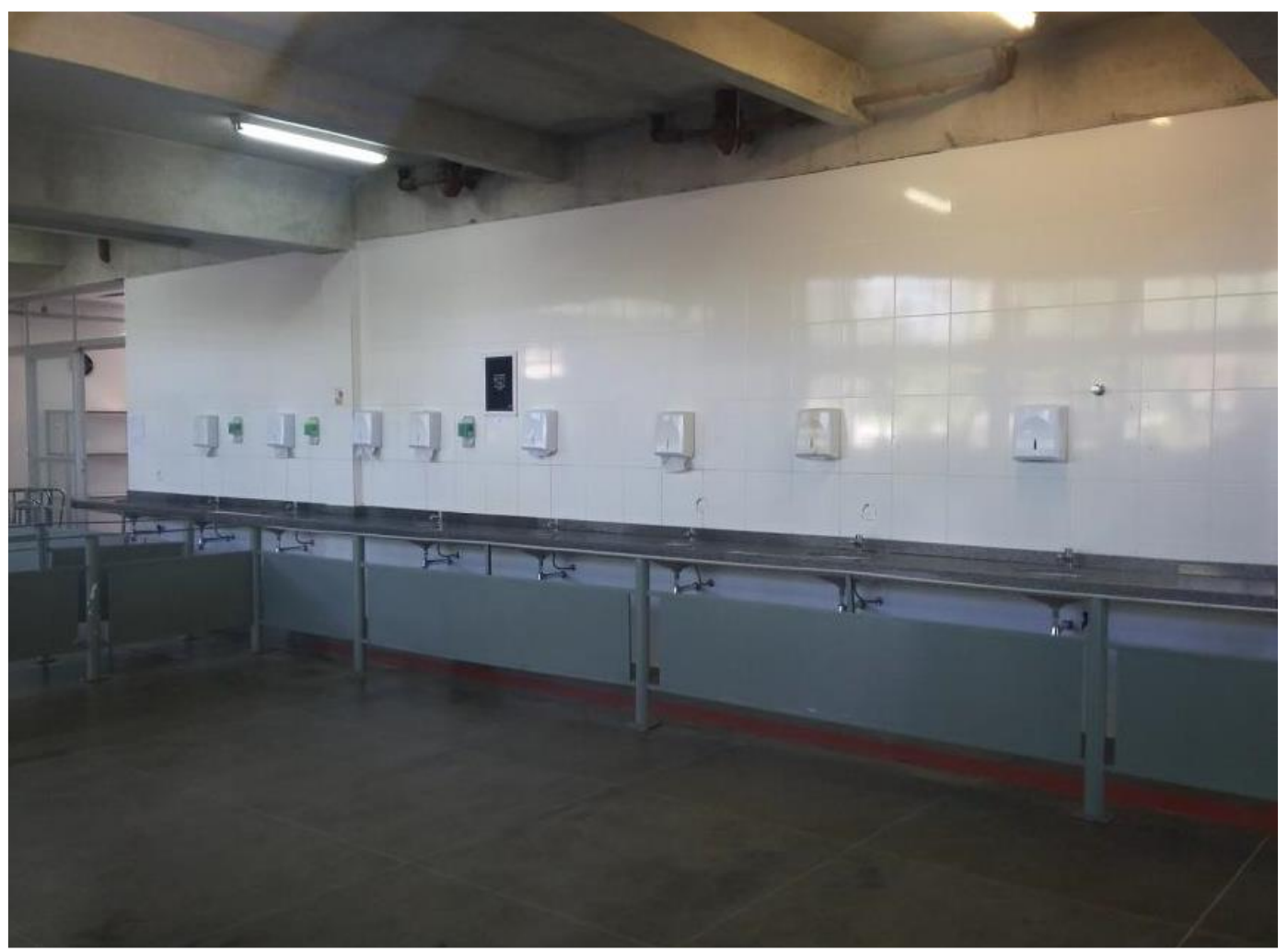

Fonte: autoria própria

Delineados os problemas, foi realizado um brainstorming para a elaboração de algumas propostas de soluções a fim de mitigá-los ou eliminá-los. As propostas de melhorias obtidas foram:

- Mudança do corrimão metálico: deslocar entrada do corrimão metálico para o início das pias, de forma todos os comensais passem obrigatoriamente por elas e possam lavar suas mãos seguindo o fluxo da fila. Além disso, estender o corrimão em ziguezague para organizar a fila na entrada do restaurante.

- Rearranjo das mesas do refeitório do térreo: mudar a disposição das mesas para gerar um melhor fluxo de pessoas e aumentar o espaço entre elas, favorecendo o 
conforto dos comensais.

- Treinamento de funcionários: em relação ao aumento de velocidade do processo, como por exemplo instruir as copeiras a usarem as duas mãos na hora de servir a proteína, e também para a orientação correta dos comensais na questão da separação do lixo, entre outras.

- Campanha de conscientização: cujo objetivo é promover as "boas práticas", evitando problemas como o fura-fila e a demora em se servir, incentivando os comensais a lavarem as mãos, evitarem o desperdício e enfatizando sobre a importância da separação correta do lixo.

A Figura 5 expõe as mudanças de layout para a entrada e o refeitório térreo, em que houve algumas modificações como a mudança de posição das mesas de horizontal para vertical. O corrimão expandido em zigue-zague e sua saída foram deslocados para o início dos lavatórios como mencionado anteriormente.

Figura 5 - Mudanças no layout do RESUN: à esquerda o corrimão em zigue-zague e à direita a disposição das mesas proposta 

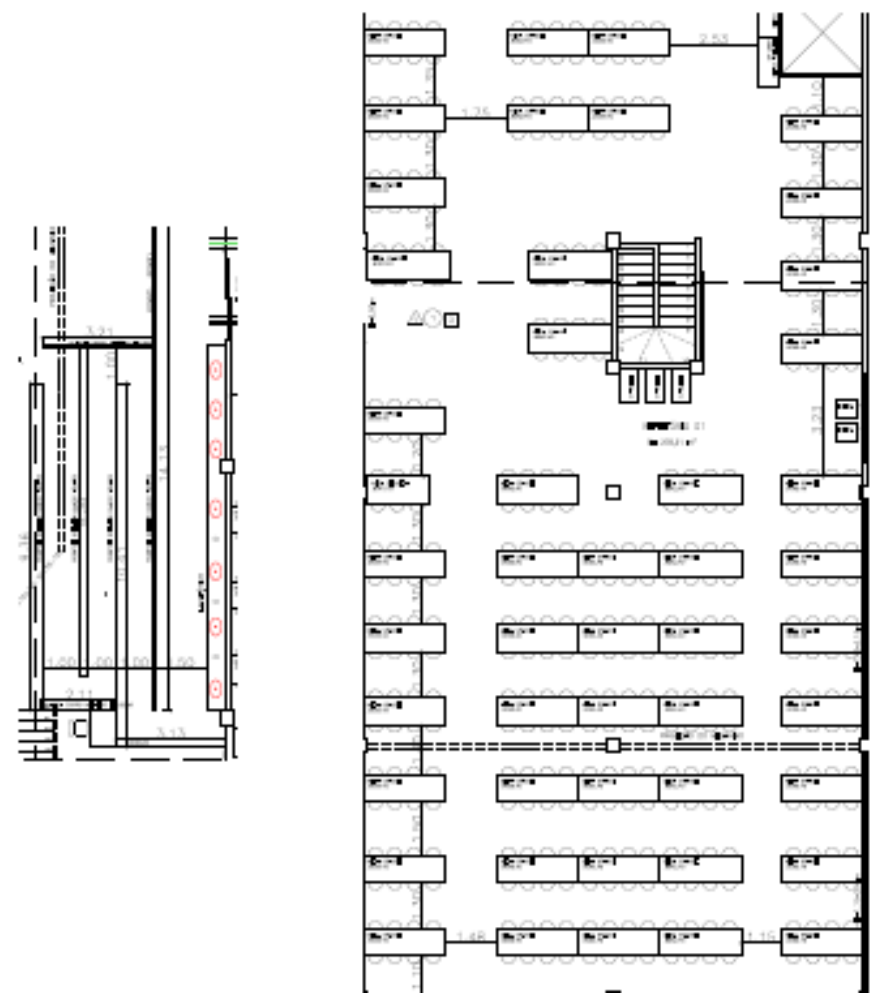

Fonte: autoria própria

\subsection{Campanha de conscientização}

O objetivo desta campanha é incentivar as "boas práticas" no RESUN. Para que ela obtenha sucesso, deve-se gerir um processo de comunicação que faça parte do cotidiano dos comensais, em sua maioria jovens estudantes, e que possa ainda atrair a atenção dos mesmos e fazê-los refletir sobre as diversas questões abordadas.

Foi realizada uma parceria com Editora UFS para o desenvolvimento desta campanha. Através de reuniões com uma equipe de estagiários coordenada por uma professora do curso de design gráfico, foram estabelecidas primeiramente as mensagens a serem transmitidas aos comensais, que foram:

- Não fure filas

- Lave as mãos antes de comer

- Não demore para pegar os alimentos 
- Evite o desperdício

- Não utilize as mesas por mais tempo que o necessário

- Separe o lixo reciclável

Tais mensagens foram trabalhadas pelos estagiários para gerarem frases a serem colocadas em pôsteres e banners. Em seguida, foram selecionados locais apropriados para fixação deste material. Os locais em destaque em termos de visualização por parte dos comensais são: as mesas, as ilhas de salada, lavatórios e lixeiras. A utilização da tipografia dos letristas, muito utilizados em comércios locais, foi uma estratégia adotada na campanha, pois é um tipo de letra com a qual muitos dos comensais estão habituados, favorecendo sua identificação com a campanha.

\section{Considerações finais}

Neste trabalho foram analisados problemas encontrados no RESUN e propostas soluções para os mesmos. Além do problema maior que era a demora no atendimento, foram abordadas outras questões que impactam no funcionamento do restaurante.

A utilização de ferramentas da qualidade e um estudo de layout levaram à elaboração de soluções através de um brainstorming e da colaboração da Editora UFS para elaboração de material de campanha de conscientização. A implementação das soluções propostas já foi iniciada, sendo que a prefeitura do campus já foi notificada e a mesma aprovou a alteração do corrimão de acesso ao restaurante dentro de seu orçamento. Após diversas reuniões realizadas periodicamente com a Editora UFS, o material da campanha já está em fase final, restando apenas a aprovação por parte da gestão do RESUN. Espera-se que no início do próximo período letivo as sugestões já estejam implementadas e surtam efeito com ajuda do Diretório Central dos Estudantes (DCE) da universidade, que se comprometeu a ajudar na divulgação da campanha na entrada do RESUN.

Deve-se destacar que as soluções implementadas tiveram como critério principal seu baixo custo, já que a universidade não dispõe atualmente de recursos em abundância que pudessem ser alocados a este projeto. O material utilizado para os corrimões já existe em 
estoque na universidade e o material gráfico será elaborado utilizando a estrutura da editora da própria universidade e um pré-existente contrato com uma gráfica.

Desta forma, pode-se considerar que os objetivos deste estudo foram atingidos, pois propostas foram desenvolvidas e um novo layout foi elaborado. $\mathrm{O}$ projeto contou com a participação de alunos do curso de engenharia de produção, gerando ainda o benefício para os mesmos de aprenderem pondo em prática seus conhecimentos em um caso real e com recursos limitados. Além disso, a equipe desempenhou uma função importante do engenheiro de produção, que é intermediar a relação entre diversos stakeholders do processo e agregar equipes com habilidades fundamentais para o projeto: comensais, reitoria da universidade e direção do RESUN como clientes; e Editora UFS, prefeitura da cidade universitária e DCE como prestadores de serviços.

\section{REFERÊNCIAS}

ANJOS, M. F.; VIEIRA, M. V. C. Mathematical optimization approaches for facility layout problems: The state-of-the-art and future research directions. European Journal of Operational Research, v. 261, p. 1-16, 2017.

CITYSISTEMS. Fluxograma de Processo - O que é, como elaborar e benefícios. Disponível em <https://www.citisystems.com.br/fluxograma/>. Acesso em 09 maio 2017.

CURY, A. Organização e métodos: uma visão holística. $7^{a}$ edição. São Paulo: Atlas, 2000. 600p.

DHAT, S.; PUND, S.; KOKARE, C.; SHARMA, P.; SHRIVASTAVA, B. Risk management and statistical multivariate analysis approach for design and optimization of satranidazole nanoparticles. European Journal of Pharmaceutical Sciences, v. 96, p. 273-283, 2017.

DIGILIO, F.; LANATI, A.; BONGIOVANNI, A.; MASCIA, A.; CARLO, M.; BARRA, A.; CIRAFICI, A.; COLOTTI, G.; KISSLINGER, A.; LACERRA, G.; LIGUORI, G. Quality-based model for Life Sciences research guidelines. Accred Qual Assur, v. 21, p. 221-230, 2016.

DOBRUSSKIN, C. On the identification of contradictions using Cause Effect Chain Analysis. Procedia CIRP, v. 39, p. 221-224, 2016.

Dupuis, J. (1996). Antropologia, cultura e organização: proposta de um modelo construtivista. In: J. Chanlat, (Coord.). O indivíduo na organização: dimensões esquecidas (Vol. 3, pp. 231-251). São Paulo: Atlas.

EELEUCH, H.; DAFAOUI, E.; MHAMEDI, A.; CHABCHOUB, H. A Quality Function Deployment approach for Production Resilience improvement in Supply Chain: Case of Agrifood Industry. IFACPapersOnLine, v. 49-31, p. 125-130, 2016. 
FILHO, H. P. O empresariado e a educação. In: FERRETTI, C. J.;ZIBAS, D. M. L.; MADEIRA, F. R. e FRANCO, M. L. (orgs.). Tecnologias, trabalho e educação - Um debate multidisciplinar. Petróplolis, RJ: Vozes, 1994.

FREITAS, A.L. A qualidade em serviço no contexto da competitividade. Florianópolis: Produção online, 2005.

GERHARDT, Tatiana Engel; SILVEIRA, Denise Tolfo. Métodos de Pesquisa. Porto Alegre: Editora da UFRGS, 2009.

GIL, A. C. Métodos e técnicas de pesquisa social. 6. ed. São Paulo: Atlas, 2008.

JORGE, G. A.; MIYAKE, D. I. Estudo comparativo das ferramentas para mapeamento das atividades executadas pelos consumidores em processos de serviço. Production, v. 26, p. 590-613, 2016.

JOZSEF, B.; BLAGA, P. A more efficient production using quality tools and human resources management. Procedia Economics and Finance, v. 3, p. 681-689, 2012.

KEMSLEY, S. Going Beyond Process Modeling: Part 1: Why Do We Manage Processes?. Bizagi, 2015. Disponível em <http://info.bizagi.com/kT0R60i00sV00SKNJ00540W>. Acesso em 09 maio 2017.

LEITE, E. M. Educação, trabalho e desenvolvimento: o resgate da qualificação. Em Aberto, Brasília, ano 15, n. 65, jan./mar. 1995.

MACHADO, L. R. de S. A educação e os desafios das novas tecnologias. In: FERRETTI, C. J.;ZIBAS, D. M. L.; MADEIRA, F. R. e FRANCO, M. L. (orgs.). Tecnologias, trabalho e educação - Um debate multidisciplinar. Petróplolis, RJ: Vozes, 1994.

MARTINS, P. G.; LAUGENI, F. P. Administração da Produção. $2^{a}$ edição. São Paulo: Saraiva, 2005. 562 p.

MITREVA, E.; CVETKOVIC, D.; FILIPOSKI, O.; METODIJESKI, D.; GJORSHEVSKI, H. Implementation of the methodology for flawless operation at a frozen food company in the Republic of Macedonia. Quality - Access to Success, v. 17, p. 98-102, 2016.

MUKHARYA, A.; PATEL, P.; SHENOY, D.; CHAUDHARY, S. Quality risk management of top spray fluidized bed process for antihypertensive drug formulation with control strategy engendered by Box-behnken experimental design space. International Journal of Pharmaceutical Investigation, v. 3, 2013.

REBELATO, M.G. Uma análise sobre a estratégia competitiva e operacional dos restaurantes self-service. São Paulo: Gestão \& Produção, v.4, n.3, p. 321-334, dez. 1997.

ROTONDARO, R.G; CAUCHICK, P.A.M; GOMES, L.A.V. Projeto do produto e do processo. São Paulo: Atlas, 2010.

SCHERMERHORN, Jr. Jonh R et alii. Fundamentos de comportamento organizacional. Porto Alegre: Bookman, 1999.

Zanelli, J. C. (no prelo). Interação humana e gestão: uma compreensão introdutória da construção organizacional. Rio de Janeiro: Editora LAB.

ZHANG, Y.; LI, X.; SU, Q. Does spatial layout matter to theme park tourism carrying capacity?. Tourism Management, v. 61, p. 82-95, 2017. 